\title{
Histopathologic changes of the radial artery wall secondary to transradial catheterization
}

\author{
This article was published in the following Dove Press journal: \\ Vascular Health and Risk Management \\ 19 June 2009 \\ Number of times this article has been viewed
}

\section{Cezar S Staniloae' \\ Kanika P Mody' \\ Kintur Sanghvi' \\ Catalin Mindrescu' \\ John T Coppola' \\ Cristina R Antonescu ${ }^{2}$ \\ Sanjay Shah ${ }^{3}$ \\ Tejas Patel ${ }^{3}$}

'Saint Vincent's Hospital Manhattan, New York, NY, USA; ${ }^{2}$ Memorial Sloan-Kettering Cancer Center, New York, NY; ${ }^{3}$ Total Cardio Vascular Solutions, Ahmedabad, India
Correspondence: Cezar S Staniloae Saint Vincent Catholic Medical Center, I70W 12th Street, Spellman 990,

New York, NY $1001 \mathrm{I}$, USA

$\mathrm{Tel}+\mathrm{I} 2126042228$

Email cstaniloae@svcmcny.org
Objective: The immediate effects of transradial access on the radial artery wall are unknown. In this study we sought to assess the histological changes induced by catheterization on the radial artery.

Methods: Thirty-four patients undergoing coronary artery bypass grafting (CABG) had radial arteries harvested to serve as bypass conduits. The proximal and distal ends of the radial artery conduits were sectioned and embedded in paraffin. Both ends of all specimens were evaluated by a blinded pathologist for intimal hyperplasia, medial inflammation, medial calcification, periarterial tissue or fat necrosis, adventitial inflammation, adventitial necrosis, and adventitial neovascularization. Fisher's exact test was used for statistical analysis.

Results: Fifteen previously catheterized radial arteries (TRA group) were compared with 19 noncatheterized arteries (NCA group). The distal ends of the TRA group showed significantly more intimal hyperplasia $(73.3 \%$ vs $21.1 \%$; $=0.03)$, periarterial tissue or fat necrosis $(26 \%$ vs $0 \% ; \mathrm{p}=0.02)$, and more adventitial inflammation $(33.3 \%$ vs $0 \%$; $\mathrm{p}=0.01)$ than the distal ends of the NCA group. The distal ends of the TRA group also showed significantly more intimal hyperplasia $(73.3 \%$ vs $26.6 \% ; \mathrm{p}=0.03)$ and adventitial inflammation $(33.3 \%$ vs $0 \% ; \mathrm{p}=0.01)$ than the proximal ends of the same arteries. There were no histological differences in the proximal ends of the two groups.

Conclusion: Transradial catheterization induces significant histological changes suggestive of radial artery injury limited to the puncture site in the form of intimal hyperplasia, medial inflammation, and tissue necrosis. Both the proximal and distal ends of the radial artery show a spectrum of atherosclerotic changes independent of its use for transradial catheterization.

Keywords: radial artery, catheterization, pathology, medial calcifications, intimal hyperplasia, atherosclerosis

\section{Introduction}

Transradial access for coronary intervention has been surrounded by increasing interest due to its clear benefits in terms of patient comfort and lower complication rates. Recent studies have shown that the transradial approach has decreased bleeding site complications as compared to the femoral approach, even in the setting of aggressive anticoagulation and antiplatelet therapies. ${ }^{1}$ The transradial approach is also associated with early ambulation, lower peri-procedure morbidity, and decreased hospital stay resulting in significant cost savings. ${ }^{2,3}$ For these reasons the transradial approach is gaining more popularity amongst patients and physicians. Nevertheless, there is a real concern about the future integrity of catheterized radial arteries (RA) as potential conduits for bypass surgery. 
The most important complications associated with transradial intervention and angiography include postprocedural RA occlusion ${ }^{4}$ and nonocclusive RA injury. ${ }^{5}$ It is also unclear what the immediate histologic changes within the arterial wall are after transradial catheterization. In this study we sought to compare the histologic findings induced by transradial catheterization on the RA with the histology of noncatheterized RAs.

\section{Methods}

\section{Study population}

Subjects scheduled to undergo coronary angiogram either via right or left RA, and deemed candidates for $\mathrm{CABG}$ were invited to participate in the study. Left radial arteries were harvested and used as bypass conduits in all patients. Patients' with history of any prior RA access, such as for coronary catheterization or arterial lines, or radial dominant hand perfusion were excluded from the study. The subjects were then divided in two groups: one group of subjects whose left RAs were just catheterized prior to harvesting (TRA group), and a second group whose right RAs were catheterized prior to left RA harvesting (NCA group). All the clinical and diagnostic procedural data were recorded. The study protocol was approved by the local Institutional Review Board.

\section{Transradial catheterization protocol}

Either the right or the left RA was used as an access site for cardiac catheterization based on a randomization table, and the corresponding area was prepared conventionally for the examination. Local anesthesia (1 $\mathrm{ml}$ of lidocaine $2 \%$ ) was administered $1 \mathrm{~cm}$ proximal to the styloid process of the radius. The RA was punctured with a 21-gauge needle, and a 0.018 -inch guide wire was introduced, followed by the insertion of a $5 \mathrm{~F}$ hydrophilic-coated sheath (Terumo Somerset, NJ, USA). After the sheath insertion, a solution containing $5 \mathrm{mg}$ of diltiazem, $2500 \mathrm{IU}$ of heparin, and $100 \mu \mathrm{g}$ of nitroglycerin was injected in the RA. During catheterization, a $260 \mathrm{~cm}$ long 0.035 -inch guide wire was positioned in the ascending aorta for catheter exchange. Immediately after the completion of the diagnostic catheterization, the sheath was removed and compression bandage was applied with just sufficient pressure to the puncture site to achieve hemostasis. The compression bandage was removed two hours after sheath removal.

\section{Radial artery biopsy protocol}

The details of RA harvesting and pharmacologic handling of the RA conduit have been the subject of previous publications. ${ }^{6,7}$ Five-millimeter biopsy sections were obtained from both the proximal and distal end of the RA conduit during harvesting. The distal biopsy specimen was $5 \mathrm{~mm}$ from the RA puncture and sheath insertion site, while the proximal biopsy was at least $15 \mathrm{~cm}$ away from the RA puncture site (Figure 1). Transverse slices of the vessels were embedded in paraffin. Sections were cut at $5 \mu \mathrm{m}$ and stained with hematoxylin and eosin. The time between the diagnostic angiogram and RA harvesting during CABG was two to three days.

\section{Microscopic examination}

The specimens were examined by a single pathologist, who was blinded to all the clinical information. Sections were qualitatively evaluated for the following changes: intimal

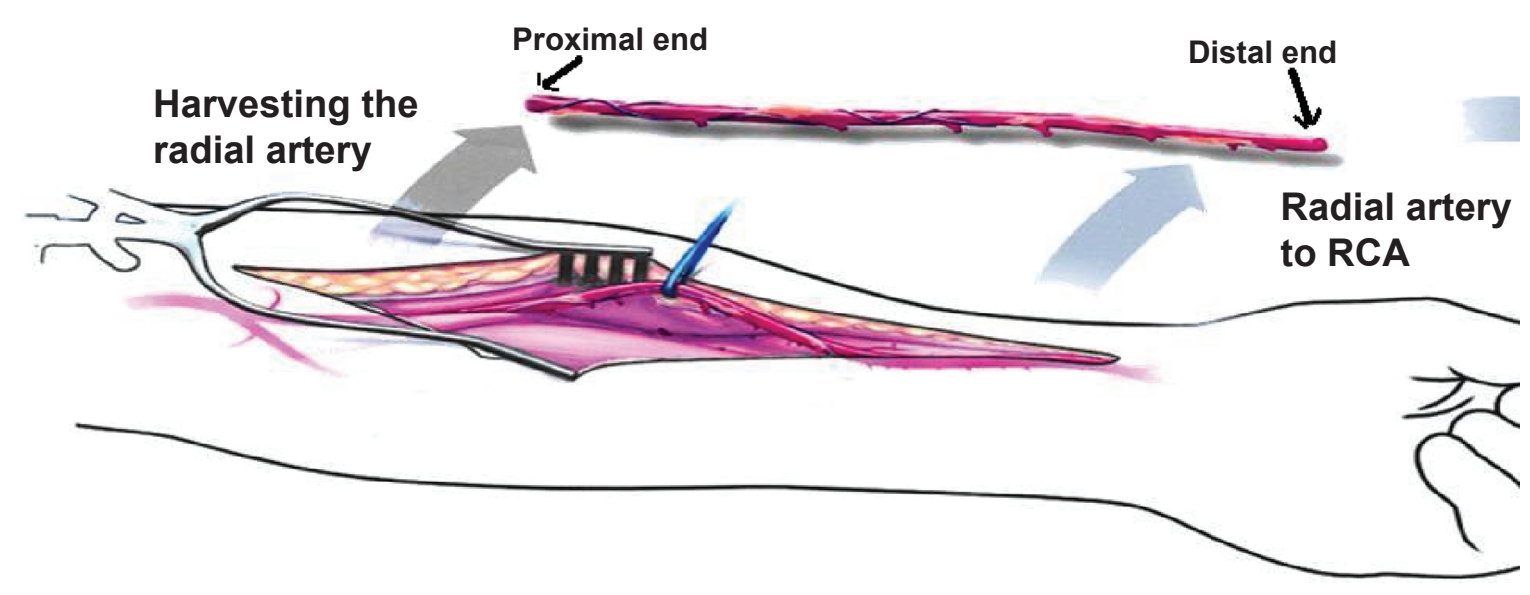

Figure I Schematic representation of the proximal and distal ends of the radial artery. Abbreviation: RCA, right coronary artery. 
hyperplasia, medial inflammation, medial calcification, periarterial tissue or fat necrosis, adventitial inflammation, adventitial necrosis, and adventitial neovascularization. Characteristic images of various findings are shown in Figure 2.

\section{Statistical analysis}

Quantitative data was expressed as mean value \pm standard deviation. Fischer's exact test was used to compare the categorical variables. $\mathrm{P}$ value of $<0.05$ was considered significant.

\section{Results}

Forty subjects were initially enrolled in the study. Six subjects, five from the TRA group and one from the NCA group, were excluded from analysis due to distorted proximal or distal RA specimens found not suitable for pathologic review. The final analysis included 34 patients; 15 patients in the TRA group and 19 in the NCA group. There were no significant differences when comparing the two groups for baseline clinical characteristics including risk factors for atherosclerosis, clinical presentation, and severity of coronary artery disease (Table 1).

The histological findings of the distal ends of RA's (in the proximity of the puncture site) are shown in Table 2 . The distal ends of the TRA group had significantly more intimal hyperplasia $(73.3 \%$ vs $21.1 \% ; \mathrm{p}=0.03)$, periarterial tissue or fat necrosis $(26 \%$ vs $0 \% ; \mathrm{p}=0.02)$, and adventitial inflammation $(33.3 \%$ vs $0 \% ; \mathrm{p}=0.01$ ) when compared to the distal ends of the NCA group. When the proximal ends of the RA conduit were compared, there were no significant histological differences between the 2 groups (Table 3 ).

The distal ends of the TRA group also had significantly higher intimal hyperplasia ( $73.3 \%$ vs $26.6 \% ; \mathrm{p}=0.018$ ) and adventitial inflammation ( $33.3 \%$ vs $0 \% ; \mathrm{p}=0.011)$, as compared to the proximal ends of the same arteries (Table 4). There were no differences between the proximal and distal ends of RA in the NCA group. Specimens from both groups showed changes consistent with various stages of atherosclerosis (intimal hyperplasia, medial calcification, hemorrhage, adventitial neovascularization).

\section{Discussion}

This is the first study examining the early histological changes induced by transradial catheterization on the RA wall. Our findings show both arterial wall injury induced by the introducer sheath as well as diffuse changes consistent with atherosclerosis of the RA unrelated to the catheterization procedure.

Transradial catheterization has gained increasing popularity in the last decade and is considered safer than the transfemoral approach. ${ }^{89}$ However, there has been concern

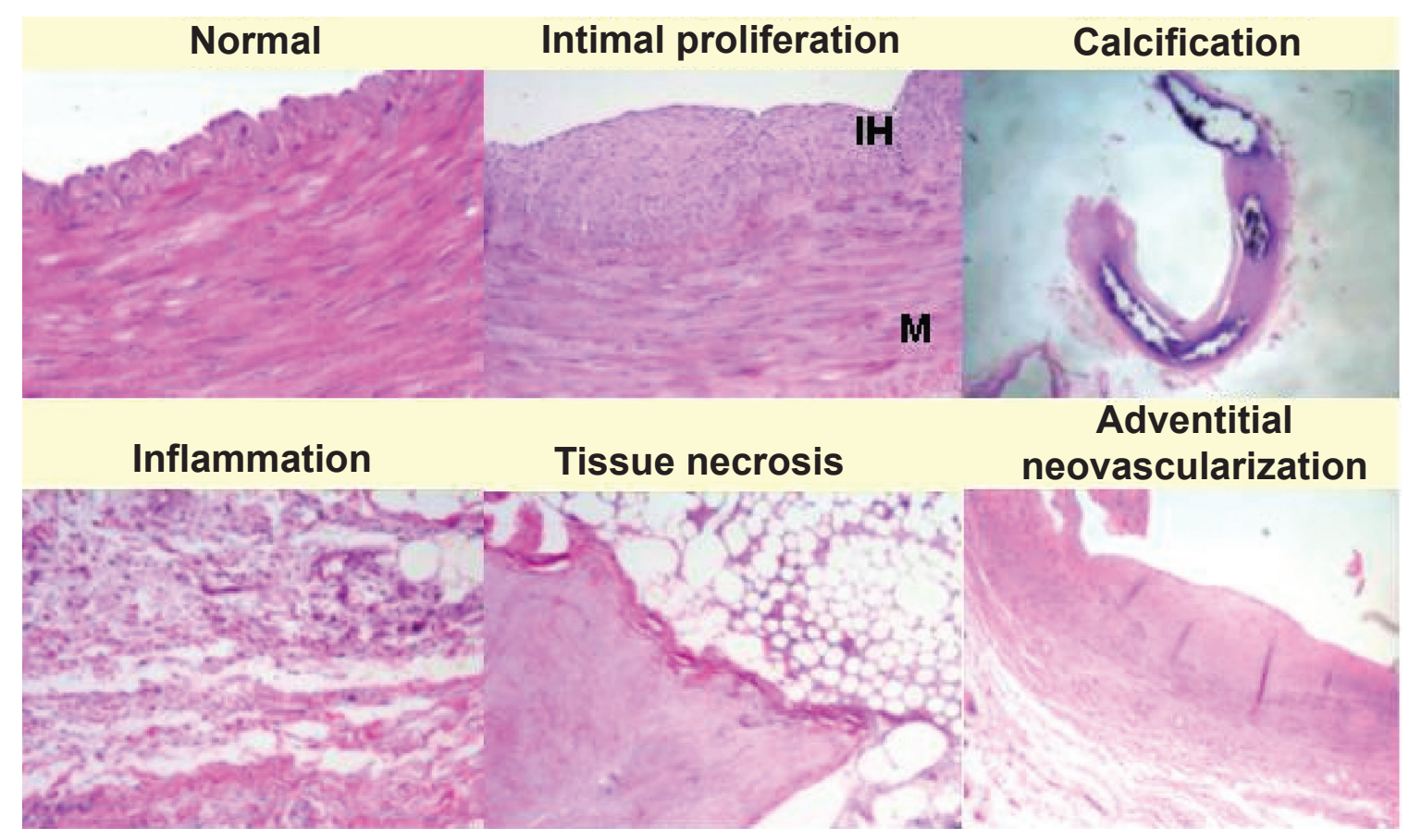

Figure 2 Representative sections of the radial artery showing different histopathological findings encountered in the study. Abbreviations: $\mathrm{IH}$, intimal hyperplasia; $\mathrm{M}$, media. 
Table I Clinical and demographic characteristics of the study population

\begin{tabular}{|c|c|c|c|}
\hline Variable & TRA group $(n=15)$ & NCA group $(n=19)$ & $P$ value \\
\hline Age, years (mean $\pm S D)$ & $59 \pm 7.2$ & $61.3 \pm 7.38$ & 0.97 \\
\hline Sex, male $(n, \%)$ & 14 (93.3\%) & $16(84.2 \%)$ & 0.51 \\
\hline $\operatorname{HTN}(n, \%)$ & $5(33.3 \%)$ & $6(31.6 \%)$ & 0.60 \\
\hline Active smoking $(\mathrm{n}, \%)$ & $2(13.6 \%)$ & $7(36.8 \%)$ & 0.12 \\
\hline Family history of CAD (n, \%) & $2(13.6 \%)$ & $6(31.6 \%)$ & 0.20 \\
\hline Diabetes $(\mathrm{n}, \%)$ & $6(40 \%)$ & $7(36.8)$ & 0.56 \\
\hline Dyslipidemia (n, \%) & $3(20 \%)$ & $6(31.6 \%)$ & 0.36 \\
\hline Clinical presentation (n, \%) & & & 0.30 \\
\hline Unstable angina & $6(40 \%)$ & $8(42.1 \%)$ & \\
\hline Chronic stable angina & $3(20 \%)$ & $2(10.5 \%)$ & \\
\hline Non ST elevation MI & $2(13.3 \%)$ & 7 (36.8\%) & \\
\hline Old MI & $2(13.3 \%)$ & $2(10.5 \%)$ & \\
\hline Congestive heart failure & $2(13.3 \%)$ & 0 & \\
\hline Coronary artery disease $(n, \%)$ & & & 0.20 \\
\hline Two vessel disease & $2(13.3 \%)$ & $5(26.3 \%)$ & \\
\hline Three vessel disease & II (73.3\%) & $13(68.4 \%)$ & \\
\hline Left main and three vessel disease & $2(13.3 \%)$ & I (5.3\%) & \\
\hline
\end{tabular}

Abbreviations: CAD, coronary artery disease; HTN, hypertension; MI, myocardial infarction; NCA, never catheterized arteries; SD, standard deviation; TRA, transradial catheterized arteries.

about the clinical significance of RA occlusion or arterial wall injury related to the potential use of the RA as a conduit for bypass surgery.

Persistent occlusion of the RA is reported in $2.8 \%$ of the cases of post-transradial catheterization. ${ }^{4}$ It is usually of little clinical consequence, and it can be minimized by the use of anticoagulation, ${ }^{10}$ immediate post-procedure sheath removal, and smaller sheath to radial artery ratio. ${ }^{11,12}$

Recently there were a few reports of permanent nonocclusive radial artery injury after transradial catheterization. Intravascular ultrasound (IVUS) studies by Wakeyama ${ }^{13}$ and Mann $^{2}$ showed luminal narrowing and intima-media thickening in the segments corresponding to sheath insertion following transradial catheterizations. The luminal narrowing was attributed to the trauma exerted by the sheath insertion, similar to denudation injury induced in animal models, rather then negative remodeling as seen in coronary restenosis after angioplasty. ${ }^{13}$ In our study we found similar changes related to injury in the distal arterial segment, characterized by tissue necrosis, intimal hyperplasia, and adventitial inflammation, while the proximal end of the RA was mostly spared from these pathological changes.

The process of intimal hyperplasia is the earliest response to endothelial injury and consists primarily of migration of medial smooth muscle cells through fenestrae of the internal elastic lamina into the intima. ${ }^{14}$

In an experimental model of arterial injury, intimal thickness as early as three days after endothelial denudation was twice that of uninjured aorta. ${ }^{15}$ In our study, there was significantly more intimal hyperplasia at the end of the artery

Table 2 Comparison of the histopathology of the distal ends of radial arteries (close to the puncture site) between TRA group vs NCA group

\begin{tabular}{llll}
\hline Variables & TRA group $(\mathbf{n}=\mathbf{I 5})$ & NCA group $(\mathbf{n}=\mathbf{I 9 )}$ & P value \\
\hline Intimal proliferation $(\mathrm{n}, \%)$ & $\mathrm{II}(73.3 \%)$ & $4(21.1 \%)$ & 0.03 \\
Medial calcification $(\mathrm{n}, \%)$ & $6(40 \%)$ & $2(10.5 \%)$ & 0.06 \\
Medial inflammation (n, \%) & $\mathrm{I}(6.7 \%)$ & 0 & 0.44 \\
Tissue/fat necrosis (n, \%) & $4(26.7 \%)$ & 0 & 0.02 \\
Adventitial inflammation (n, \%) & $5(33.3 \%)$ & 0 & 0.01 \\
Adventitial necrosis (n, \%) & $2(13.3 \%)$ & 0 & 0.18 \\
Adventitial neovascularization (n, \%) & 0 & $3(15.8 \%)$ & 0.16 \\
\hline
\end{tabular}

Abbreviations: NCA, never catheterized arteries; TRA, transradial catheterized arteries. 
Table 3 Comparison of the histopathology of the proximal ends (away from the puncture site) of radial arteries between TRA group and NCA group

\begin{tabular}{llll}
\hline Variables & TRA group $(\mathbf{n}=\mathbf{~ 1 5 )}$ & NCA group $(\mathbf{n}=\mathbf{~ I 9 )}$ & P value \\
\hline Intimal proliferation $(\mathrm{n}, \%)$ & $4(36.7 \%)$ & $\mathrm{I}(5.3 \%)$ & 0.074 \\
Medial calcification (n, \%) & $4(36.7 \%)$ & $3(15.8 \%)$ & $0.28 \mathrm{I}$ \\
Medial inflammation (n, \%) & $\mathrm{I}(6.7 \%)$ & 0 & 0.406 \\
Tissue/fat necrosis (n, \%) & $2(13.3 \%)$ & 0 & 0.157 \\
Adventitial inflammation (n, \%) & 0 & 0 & 0.157 \\
Adventitial necrosis (n, \%) & $2(13.3 \%)$ & 0 & 0.559 \\
Adventitial neovascularization (n, \%) & 0 & $\mathrm{I}(5.3 \%)$ & \\
\hline
\end{tabular}

Abbreviations: NCA, never catheterized arteries;TRA, transradial catheterized arteries.

injured by the introducer sheath when compared to arteries that were never injured. The same findings were observed when the distal ends of the arteries were compared with the more proximal ends, supporting the concept that endothelial denudation is the major trigger of the process. On the other hand, our study found a statistically nonsignificant trend towards more intimal hyperplasia and tissue necrosis in the proximal ends of the TRA group when compared with the NCA group. These findings could be due to chance, or they may suggest potentially diffused arterial damage induced by the introducer sheath. This hypothesis was previously explored by Nagai and colleagues ${ }^{12}$ who showed progressive, chronic reduction on the diameter of the radial artery measured by Duplex ultrasound two days and 4-6 months after transradial catheterization. Very similar results were obtained by Kamiya and colleagues ${ }^{14}$ who compared angiographic and pathologic findings of RAs used as conduits for coronary artery bypass between patients who underwent transradial catheterization and those who did not. The mean time interval between the preoperative catheterization and bypass surgery was 46 days, and follow-up angiography was performed one month after surgery. Intimal hyperplasia of the radial artery was seen in $68 \%$ of previously catheterized RA and $39 \%$ in noncatheterized RA. The authors noted that the grafts used in prior transradial catheterization also showed higher failure rates. ${ }^{14}$

Medial calcification was seen frequently (10\% to $40 \%)$ in both the distal and proximal ends of RA in both groups of subjects. Since the time between the catheterization and the RA harvesting was only 72 hours, we concluded that these findings were related to chronic atherosclerosis rather than secondary to the arterial wall injury during catheterization. The higher but statistically nonsignificant presence of medial calcification in the TRA group may suggest that this group of patients could have had a higher atherosclerotic burden than the NCA group.

An IVUS study of the radial arteries by Oshima and colleagues ${ }^{16}$ showed that $6.9 \%$ of patients had greater than $50 \%$ plaque area and $8.6 \%$ patients had medial calcifications. In a pathological analysis of 150 distal RA conduits, Ruengsakulrach and colleagues ${ }^{17}$ observed that more than $5 \%$ of the RAs had significant atherosclerosis and more than $13 \%$ of the RAs displayed medial calcification. This is in concordance with our findings, which revealed that both the proximal and distal ends of the radial arteries show a spectrum of atherosclerotic changes, from intimal hyperplasia to severe circumferential calcifications irrespective of whether or not they were utilized for catheterization access.

Table 4 Comparison between the histopathology of the proximal end and the distal end of radial arteries in the TRA group

\begin{tabular}{llll}
\hline Variables & Distal end $(\mathbf{n}=\mathbf{I 5})$ & Proximal end $(\mathbf{n}=\mathbf{I 5})$ & P value \\
\hline Intimal proliferation $(\mathrm{n}, \%)$ & $\mathrm{II}(73.3 \%)$ & $4(26.6 \%)$ & 0.018 \\
Medial calcification $(\mathrm{n}, \%)$ & $6(40 \%)$ & $4(26.6 \%)$ & 0.337 \\
Medial inflammation (n, \%) & $\mathrm{I}(6.6 \%)$ & $\mathrm{I}(6.6 \%)$ & $\mathrm{I}$ \\
Tissue/fat necrosis (n, \%) & $4(26.6 \%)$ & $2(13.3 \%)$ & 0.337 \\
Adventitial inflammation (n, \%) & $5(33.3 \%)$ & 0 & $0.01 \mathrm{I}$ \\
Adventitial necrosis (n, \%) & $2(13.3 \%)$ & $2(13.3 \%)$ & 0.339 \\
Adventitial neovascularization (n, \%) & $2(13.3 \%)$ & $2(13.3 \%)$ & 0.339 \\
\hline
\end{tabular}

Abbreviation: TRA, transradial catheterized arteries. 
These findings suggest an inherent tendency of RA for atherosclerosis, and help differentiate the radial artery from the internal thoracic artery as conduits for bypass surgery.

The present study offers a possible histological explanation to the concerns raised by various clinical studies regarding the disappointing short and long-term outcome of radial arteries when used as bypass conduits. In a randomized study enrolling 561 patients, Desai and colleagues ${ }^{18}$ reported $8.2 \%$ radial graft occlusion and $7 \%$ of radial grafts having diffused narrowing at the end of one year. Khot and colleagues ${ }^{19}$ concluded in an observational study that radial grafts had an increased incidence of angiographically severe stenosis and occlusion as compared to the internal mammary artery and even vein grafts.

Although the small number of patients and the lack of clinical follow-up limited the current study, the histologic findings suggest that the RA is susceptible to atherosclerosis. Although transradial catheterization is associated with increased inflammatory changes in the arterial wall, these changes seem to be limited to the proximity to the access site. While further clinical outcome studies are needed to determine the implications of these histological findings, this study does show that while transradial catheterization induces inflammatory and possibly pro-stenotic changes in the distal RA, the proximal segment of the RA is less affected. Therefore, in the absence of clinical data, the proximal segment of the artery could theoretically be considered as a bypass conduit even in the setting of prior transradial catheterization.

\section{Disclosure}

The authors report no conflicts of interest in this work.

\section{References}

1. Philippe F, Larrazet F, Meziane T, Dibie A. Comparison of transradial vs transfemoral approach in the treatment of acute myocardial infarction with primary angioplasty and abciximab. Catheter Cardiovasc Interv. 2004;61(1):67-73.

2. Mann T, Cubeddu G, Bowen J, et al. Stenting in acute coronary syndromes: a comparison of radial versus femoral access sites. $\mathrm{J} \mathrm{Am}$ Coll Cardiol. 1998;32(3):572-576.

3. Cooper CJ, El-Shiekh RA, Cohen DJ, et al. Effect of transradial access on quality of life and cost of cardiac catheterization: A randomized comparison. Am Heart J. 1999;138(3 Pt 1):430-436.

Vascular Health and Risk Management

\section{Publish your work in this journal}

Vascular Health and Risk Management is an international, peerreviewed journal of therapeutics and risk management, focusing on concise rapid reporting of clinical studies on the processes involved in the maintenance of vascular health; the monitoring, prevention and treatment of vascular disease and its sequelae; and the involvement of
4. Stella PR, Kiemeneij F, Laarman GJ, Odekerken D, Slagboom T, van der Wieken R. Incidence and outcome of radial artery occlusion following transradial artery coronary angioplasty. Cathet Cardiovasc Diagn. 1997;40(2):156-158.

5. Edmundson A, Mann T. Nonocclusive radial artery injury resulting from transradial coronary interventions: radial artery IVUS. I Invasive Cardiol. 2005;17(10):528-531.

6. Reyes AT, Frame R, Brodman RF. Technique for harvesting the radial artery as a coronary artery bypass graft. Ann Thorac Surg. 1995;59(1):118-126.

7. Fremes SE, Christakis GT, Del Rizzo DF, Musiani A, Mallidi H, Goldman BS. The technique of radial artery bypass grafting and early clinical results. J Card Surg. 1995;10(5):537-544.

8. Agostoni P, Biondi-Zoccai GG, de Benedictis ML, et al. Radial versus femoral approach for percutaneous coronary diagnostic and interventional procedures; Systematic overview and meta-analysis of randomized trials. J Am Coll Cardiol. 2004;44(2):349-356.

9. Jolly S AS, Hamon M, Yusuf S, Phil D, Mehta S. Radial versus femoral access for coronary angiography or intervention and the impact on major bleeding and ischemic events: A systematic review and meta-analysis of randomized trials. Am Heart J. 2009;57:132-140.

10. Spaulding $C$, Lefevre $T$, Funck F, et al. Left radial approach for coronary angiography: results of a prospective study. Cathet Cardiovasc Diagn. 1996;39(4):365-370.

11. Saito S, Ikei H, Hosokawa G, Tanaka S. Influence of the ratio between radial artery inner diameter and sheath outer diameter on radial artery flow after transradial coronary intervention. Catheter Cardiovasc Interv. 1999;46(2):173-178.

12. Nagai S, Abe S, Sato T, et al. Ultrasonic assessment of vascular complications in coronary angiography and angioplasty after transradial approach. Am J Cardiol. 1999;83(2):180-186.

13. Wakeyama $\mathrm{T}$, Ogawa $\mathrm{H}$, Iida $\mathrm{H}$, et al. Intima-media thickening of the radial artery after transradial intervention. An intravascular ultrasound study. J Am Coll Cardiol. 2003;41(7):1109-1114.

14. Kamiya H, Ushijima $T$, Kanamori $T$, et al. Use of the radial artery graft after transradial catheterization: is it suitable as a bypass conduit? Ann Thorac Surg. 2003;76:1505-1509.

15. Hariri RJ, Alonso DR, Hajjar DP, Coletti D, Weksler ME. Aging and arteriosclerosis. I. Development of myointimal hyperplasia after endothelial injury. J Exp Med. 1986;164(4):1171-1178.

16. Oshima A, Takeshita S, Kozuma K, et al. Intravascular ultrasound analysis of the radial artery for coronary artery bypass grafting. Ann Thorac Surg. 2005;79(1):99-103.

17. Ruengsakulrach P, Sinclair R, Komeda M, Raman J, Gordon I, Buxton B. Comparative histopathology of radial artery versus internal thoracic artery and risk factors for development of intimal hyperplasia and atherosclerosis. Circulation. 1999;100(19 Suppl):II139-II144.

18. Desai ND, Cohen EA, Naylor CD, Fremes SE. A randomized comparison of radial-artery and saphenous-vein coronary bypass grafts. $N$ Engl J Med. 2004;351(22):2302-2309.

19. Khot UN, Friedman DT, Pettersson G, Smedira NG, Li J, Ellis SG. Radial artery bypass grafts have an increased occurrence of angiographically severe stenosis and occlusion compared with left internal mammary arteries and saphenous vein grafts. Circulation. 2004;109(17):2086-2091.

metabolic disorders, particularly diabetes. This journal is indexed on PubMed Central and MedLine. The manuscript management system is completely online and includes a very quick and fair peer-review system, which is all easy to use. Visit http://www.dovepress.com/ testimonials.php to read real quotes from published authors. 